\title{
INDÍCIOS DE INSUBORDINAÇÃO CRIATIVA NA TESE DE DOUTORADO DE BEATRIZ D'AMBROSIO: DINÂMICAS E AS CONSEQUÊNCIAS DO MOVIMENTO DA MATEMÁTICA MODERNA NA EDUCAÇÃO MATEMÁTICA DO BRASIL
}

\author{
CREATIVE INSUBORDINATION'S INDICATIONS IN THE BEATRIZ D'AMBROSIO'S \\ THESIS: THE DYNAMICS AND CONSEQUENCES OF THE MODERN MATHEMATICS \\ REFORM MOVEMENT FOR BRAZILIAN MATHEMATICS EDUCATION
}

\author{
Josâne Geralda Barbosa ${ }^{1}$ \\ Instituto Federal de Minas Gerais - Campus Ouro Preto/CEAD \\ josane.barbosa@ifmg.edu.br
}

\section{Resumo}

Este texto traz um estudo da tese de doutorado da professora Beatriz Silva D'Ambrosio, apresentada em 1987 à Faculdade de Filosofia da Indiana University Bloomington/Estados Unidos, para obtenção do título de doutora em Filosofia. Busca-se evidenciar os indícios de aproximação com as ideias de insubordinação criativa na pesquisa em que ela analisou o processo de transferência do currículo da Matemática Moderna de países da América do Norte e da Europa para o Brasil. Na contextualização do trabalho, Beatriz reflete sobre a dependência - quanto à produção e à divulgação do conhecimento - dos países menos desenvolvidos em relação a países desenvolvidos, sobre a realidade educacional nesses países menos desenvolvidos e sobre a comunicação das inovações de países desenvolvidos para os menos desenvolvidos. A partir de entrevistas semiestruturadas e análise bibliográfica, organiza e discute,em dez grandes temas, os dados coletados. Baseada nessas discussões, apresenta suas conclusões relacionadas à dinâmica do movimento da Matemática Moderna no Brasil e finaliza indicando onze recomendações importantes para momentos de discussão, formulação e implementação de políticas educacionais.

Palavras-chave: Insubordinação criativa. Matemática Moderna. Currículo. Educação Matemática.

\section{Abstract}

This work presents a review of the doctoral thesis of Professor Beatriz da Silva D'Ambrosio, presented in 1987, to the Faculty of Philosophy of Indiana University Bloomington / United States, to obtain a PhD in Philosophy. It is sought to evidence the signs of approach to the ideas of creative insubordination in her research, when the author

\footnotetext{
${ }^{1}$ Agradeço à Leda Maria de Souza Freitas Farah, que carinhosamente procedeu a revisão do artigo.
} 
analyzed the process of transferring the curriculum of Modern Mathematics from North American and European countries to Brazil. In the contextualization of the work Beatriz presents a reflection on the dependence of less developed countries on developed countries (in the production and dissemination of knowledge), the educational reality in these less developed countries and the communication of innovations from developed to less developed countries. From semi-structured interviews and bibliographic analysis, the author organizes and discusses the data collected in ten major themes. Based on these discussions, the author presents her conclusions related to the dynamics of the modern mathematics movement in Brazil and ends by indicating eleven important recommendations for moments of discussion, formulation and implementation of educational policies.

Keywords: Creative insubordination. Modern Mathematics. Curriculum. Mathematical Education.

\section{Introdução}

Pretende-se, neste artigo, apresentar um estudo da tese de doutorado da professora Beatriz Silva D’Ambrosio, evidenciando os indícios de sua aproximação com as ideias de insubordinação criativa, na pesquisa em que analisou o processo de transferência do currículo da Matemática Moderna, de países da América do Norte e da Europa, para o Brasil. A tese, sob a orientação pelo professor Frank K. Lester Jr., foi apresentada em 1987 à Faculdade de Filosofia da Indiana University Bloomington/Estados Unidos, para obtenção do título de doutora em Filosofia.

A professora Beatriz Silva D’Ambrosio nasceu em 26 de janeiro de 1960, na cidade de São Paulo/SP, Brasil. Aos 2 anos de idade mudou-se para os Estados Unidos, onde frequentou os primeiros anos do Ensino Fundamental. Com 12 anos, retornou ao Brasil e concluiu os Ensinos Fundamental e Médio. Cursou Licenciatura em Matemática na Universidade Estadual de Campinas (Unicamp), no estado de São Paulo, Brasil e, ao término da graduação, regressou aos Estados Unidos, onde cursou o mestrado em Educação Matemática e o doutorado em Filosofia, ambos na Indiana University Bloomington.

Em sua trajetória profissional, Beatriz lecionou em quatro universidades norteamericanas: Universidade de Indiana (IU), em Bloomington/Indiana; Universidade de Miami, em Oxford/Ohio; Faculdade de Educação da Universidade da Geórgia, em Athens/Geórgia; e Escola de Educação da Universidade de Delaware, em Newark/New Jersey. Também lecionou em três universidades brasileiras: Universidade Estadual de Campinas - Unicamp/São Paulo, Universidade Estadual Paulista Julio de Mesquita Filho - Unesp/São Paulo e Pontifícia Universidade Católica de São Paulo - PUC/SP, e em uma instituição educacional brasileira para crianças com dificuldades de aprendizagem.

Em setembro de 2015, quando residia em Ohio/Estados Unidos, Beatriz faleceu, vítima de um aneurisma cerebral, deixando valiosas contribuições nas áreas da 
Matemática, Educação Matemática, Currículo, Ensino e Aprendizagem de Matemática e Formação de Professores.

$\mathrm{Na}$ tese de doutorado, Beatriz tinha como principal objetivo analisar o movimento de reforma da Matemática Moderna no Brasil, com enfoque particular na dinâmica do movimento e suas consequências para a Educação Matemática brasileira. A pesquisa é qualitativa e utilizou-se de instrumentos como entrevistas semiestruturadas, que envolveram autores de livros didáticos; especialistas estrangeiros que foram consultores no Brasil; professores brasileiros que lecionavam no Ensino Superior; professores que participaram de cursos e treinamentos no Brasil ou no exterior; professores que lecionavam na formação de professores; professores que ministraram cursos e oficinas; diversos professores e funcionários de órgãos governamentais. Valeu-se também de análise bibliográfica, que envolveu reportagens da imprensa, livros didáticos, anais de congressos nacionais de educação matemática e artigos publicados antes da reforma.

$\mathrm{Na}$ contextualização do trabalho, Beatriz apresenta uma reflexão sobre a dependência dos países menos desenvolvidos em relação aos países desenvolvidos, com enfoque na produção e na divulgação do conhecimento. Também discute a realidade educacional nos países menos desenvolvidos e reflete sobre a comunicação das inovações desenvolvidas em países do Primeiro Mundo para países do Terceiro Mundo, cujo enfoque está nas pesquisas sobre a transferência do currículo de matemática dos países desenvolvidos para os países em desenvolvimento.

As inquietações que envolviam Beatriz e motivaram a pesquisa foram muitas: A matemática ensinada nas escolas dos países em desenvolvimento deve ser a mesma que a ensinada nos países industrializados? Quais são os canais através dos quais uma inovação atinge um grupo de pessoas? Em que medida o currículo da Matemática Moderna era apropriado para o desenvolvimento do Brasil? Quais foram as influências de órgãos e agências estrangeiras sobre os currículos e sobre os responsáveis brasileiros pelas decisões? Qual a pertinência da reforma para a realidade sociocultural brasileira, considerando a natureza da sociedade, das crianças, dos professores e da própria Matemática? Num dos vários momentos de inquietação e insatisfação com a realidade posta, Beatriz apresenta estas e tantas outras questões e, para responder, discorre em seu referencial teórico sobre a história da educação brasileira desde 1545, no Brasil Colônia, até 1971, com a análise da Lei 5.692/1971, passando pela primeira Lei de Diretrizes e Bases (LDB), a Lei 4.024/1961. Analisa, sob uma perspectiva crítica, essas leis e os impactos que provocaram.

Quando observamos as questões elencadas por Bia, podemos associá-las às ideias que mais tarde ela iria discutir e publicar em coautoria com Lopes, ao considerarem que a

insubordinação criativa é ter consciência sobre quando, como e por que agir contra procedimentos e diretrizes estabelecidas. Ser subversivamente responsávelrequer assumir-se como ser inconcluso, que toma a curiosidade como alicerce da produção do conhecimento e faz de seu inacabamento um permanente movimento de busca (D'AMBROSIO; LOPES, 2014, p. 29). 
Beatriz já assumia, em sua pesquisa de doutorado, uma postura subversivamente responsável, ao revelar ponderações e questionamentos sobre a história do movimento da Matemática Moderna nos diversos países, ressaltando as questões sociais, econômicas e políticas que se apresentavam nas tomadas de decisões dos países envolvidos.

\section{Perspectiva histórica da educação brasileira}

Segundo Bia, o sistema educacional brasileiro foi, por muito tempo, acadêmico e aristocrático, totalmente voltado para a educação da elite. A partir da Primeira Guerra Mundial, mudaram-se as estruturas da economia e, com a aceleração do processo de industrialização no Brasil, educadores começaram a analisar e discutir propostas para melhorar o cenário educacional brasileiro. Surgiu, por volta de 1930, o movimento da Escola Nova, que propunha a democratização da educação, aumentando o número de instituições e de estudantes atendidos. Apesar do aumento do número de escolas, de estudantes e de professores, não se observou uma melhoria significativa na qualidade da educação brasileira. Beatriz relata a elevação dos índices de reprovação e de abandono e a separação entre o ensino profissionalizante e o ensino exclusivamente acadêmico. A motivação para o ensino profissionalizante, que recebeu forte incentivo no período de ditadura militar e foi pensado para as classes menos favorecidas, era a necessidade de formação de mão de obra para o trabalho.

Ela destaca a estruturação do sistema educacional, com a Lei 4.024/1961 (primeira LDB brasileira), em Ensino Primário, de quatro anos, e Ensino Secundário, de sete anos, divididos em um curso de quatro anos e outro de três, que equivalem aos atuais Anos Iniciais, Anos Finais do Ensino Fundamental e Ensino Médio, respectivamente. Essa lei também estipulava a realização, entre o Ensino Primário e o Secundário, do exame de admissão, que restringia o acesso de muitas crianças à Educação Secundária. Também instituiu o exame de vestibular para acesso às universidades.

A aprovação da Lei 5.692, de 1971, que Beatriz considera uma real reforma do sistema educacional brasileiro, baseada nas necessidades internas e não em um modelo importado, instituiu o Primeiro Grau com duração de oito anos, oferecido pelos estados e gratuito para todas as crianças, e o Segundo Grau, com duração de três anos, que propunha também alguma formação profissional e técnica, permitindo o acesso ao mercado de trabalho.

No entanto, essa reforma não conseguiu atingir plenamente seus objetivos: sofreu resistências por parte da sociedade tradicional; faltaram recursos humanos, financeiros e materiais que garantissem o cumprimento da lei; as escolas implementaram os cursos profissionalizantes de acordo com as exigências constantes no currículo do curso (laboratório, profissionais, tempo de duração, dentre outras) e não de acordo com as necessidades da sociedade em que estavam inseridas; não houve adequado apoio e orientação às escolas e aos profissionais e ocorreu forte rejeição dos opositores ao regime militar, que o fizeram sem analisar e considerar os benefícios que a reforma poderia trazer. Segundo a autora Beatriz, essa lei acabou não promovendo alteração significativa no currículo de matemática. 


\section{O Movimento da Matemática Moderna}

Procurando as raízes das inspirações para as reformas no currículo de matemática no Brasil, Bia autora relata a influência dos Estados Unidos e de pesquisadores de outros países. Segundo ela, o Movimento da Matemática Moderna nos Estados Unidos foi o maior movimento de reforma na história da Educação Matemática, que incluía, como principais modificações no ensino da Matemática: o método dedutivo, o desenvolvimento da teoria de conjuntos, a definição de números naturais com base em conceitos de conjuntos, o desenvolvimento de novos padrões de rigor, a evolução da geometria não euclidiana e a evolução da álgebra abstrata. Tais modificações representaram um novo olhar sobre a matemática pelos próprios matemáticos e indicaram um caminho de preparação dos estudantes para o ingresso nas universidades.

O ingresso de jovens com formação matemática deficiente nas Forças Armadas americanas durante a Segunda Guerra Mundial foi considerado alarmante e problemático para os Estados Unidos. Após a guerra, foi redefinido o objetivo do ensino de Matemática, com vistas à sociedade tecnológica de rápido desenvolvimento. O currículo de Matemática em outros cursos das universidades que usavam a matemática aplicada também foi alterado, em decorrência dessas deficiências. Em 1951 foi criado o Comitê de Matemática Escolar da Universidade de Illinois (University of Illinois Comittee on School Mathematics - UICSM), que desenvolveu e testou materiais didáticos, além de capacitar professores para utilizá-los no Ensino Médio, com foco na precisão da linguagem e na aprendizagem por meio da descoberta. Esse foi considerado o primeiro grande projeto a buscar a melhoria do currículo de matemática no nível médio.

Outros grupos se formaram, em outras universidades americanas, além do UICSM. $\mathrm{E}$, apesar das indicações de reformas necessárias, foi o lançamento do satélite soviético Sputnikque levou os Estados Unidos a perceber que não tinham mais a soberania nas ciências e nas tecnologias e a procurar por reformas, com vistas a melhorar a qualidade da educação no ensino secundário. Assim, foi fundado, na Universidade de Yale, o Grupo de Estudos da Matemática Escolar (School Mathematics Study Group - SMSG), com a participação de matemáticos, professores de matemática, educadores, psicólogos e representantes da comunidade científica e tecnológica, responsáveis pela elaboração de material didático para o Ensino Médio. Esses materiais foram traduzidos para 15 idiomas diferentes, o que levou a influência da Matemática Moderna para todo o mundo.

Além do SMSG, diversos outros grupos, citados por Bia, foram responsáveis pelo desenvolvimento de materiais didáticos para os Ensinosde Primeiro e Segundo Grau, seguindo as premissas da Matemática Moderna: linguagem matemática precisa e aprendizagem por descoberta. Esses grupos também se ocuparam da capacitação de professores para utilizar os materiais didáticos desenvolvidos, embora, segundo argumentos de Bia, a maioria dos professores, especialmente os do Ensino Fundamental, não tenha sido capacitada. Os cursos acabaram concentrando-se nos professores do nível secundário e em conteúdos matemáticos, ao invés de investir na utilização dos novos materiais didáticos. 
Dentre as muitas críticas apresentadas ao Movimento da Matemática Moderna, Beatriz destaca quatro: os novos tópicos incluídos no currículo (lógica, teoria de conjuntos, álgebra abstrata e topologia), que foram considerados inúteis para o cotidiano dos alunos; a presença de demonstrações excessivas (principalmente para teoremas óbvios); os muitos tópicos demasiadamente abstratos; e a ênfase na linguagem precisa, que foi considerada prejudicial por aumentar a memorização. A principal crítica feita por professores de matemática respeitados nos Estados Unidos, apontado por Beatriz, se refere à inadequação da Matemática Moderna para o Ensino Fundamental.

\section{O Movimento da Matemática Moderna no Brasil}

A proposta da Matemática Moderna consistia em uma alternativa ao ensino tradicional e, por meio da introdução de novas organizações curriculares e de novos métodos de ensino (GUIMARÃES, 2007), pretendia modificar os currículos do ensino da Matemática.

Matemática Moderna é a matemática tradicional reformulada em novas bases, colocando nosso ensino e pesquisa em paridade com os dos países desenvolvidos do mundo, de modo a atender não somente as necessidades mais importantes e inadiáveis da vida prática como também as de caráter técnico-científico e industrial. (GUIMARÃES, 1963 apud D’AMBROSIO, 2017, p. 132)

A preocupação de Beatriz consistia em determinar como as ideias sobre o currículo de matemática moderna chegaram ao Brasil e em que medida o currículo de matemática moderna era apropriado para o desenvolvimento do Brasil.

A partir dessas questões, outras surgiram na tese: "Quais são os canais através dos quaisuma inovação atinge um grupo de pessoas?", "Se as 'necessidades' são criadas a partir do conhecimento de uma inovação, então como esse conhecimento chega até o grupo?", "Quais foram as influências dos órgãos estrangeiros de assistência sobre os planejadores de currículos e sobre os responsáveis brasileiros pelas decisões?", "O Brasil solicitou auxílio para adotar o programa da matemática moderna ou o programa foi oferecido ao Brasil? (Caso tenha sido oferecido, por quê?)", "A ideia da matemática moderna foi sugerida aos brasileiros por especialistas estrangeiros ou já existia, quando os especialistas foram consultados?", "Os projetos de matemática moderna foram elaborados por órgãos estrangeiros e sugeridos para adoção ou foram elaborados no Brasil, por instituições locais?", "Como os alunos de pós-graduação e membros do corpo docente brasileiros que viajaram ao exterior para adquirir maior formação em educação ou em matemática influenciaram a incorporação da matemática moderna no currículo do ensino fundamental?", "Os projetos para a redação dos livros didáticos estavam ligados às universidades?", "Os autores dos livros didáticos eram comissionados para redigir os textos ou eles entravam em acordo sobre a concepção de tais livros exclusivamente com as editoras?", "Eram projetos de tradução de textos americanos ou foram redigidos a partir do zero?", "Os projetos de formação de professores (tanto professores em serviço como aqueles em formação) foram auxiliados por órgãos e especialistas estrangeiros ou foram basicamente desenvolvidos no país?", "Os planejadores brasileiros de currículos eram ligados às universidades e/ou ao Ministério de Educação?”, "Qual foi o grau de 
participação dos educadores brasileiros em conferências internacionais nas quais o principal problema discutido foi o currículo de matemática moderna?", "Quais eram as publicações de distribuição internacional disponíveis para os planejadores e tomadores de decisões brasileiros?", "O currículo proposto era adequado à sociedade brasileira?", "O conteúdo de matemática proposto pelo novo currículo era relevante para as seguintes necessidades: Necessidades de desenvolvimento econômico da nação, necessidades das crianças e de seu papel na sociedade e necessidades das crianças e de seu papel futuro como adultos?"e, finalmente, "O processo de adoção da inovação procurou lidar com as necessidades sentidas pelos professores brasileiros de matemática antes da adoção?". Tantas perguntas demonstram uma pesquisadora que visualiza o complexo movimento da reforma e suas vertentes; que questiona a aplicabilidade, a necessidade e a pertinência da reforma tal como foi realizada; e que se aventura num estudo complexo e cheio de incertezas.

O Brasil sofreu grandes influências da reforma empreendida nos Estados Unidos e na França. Ao final do segundo capítulo, alguns outros estudiosos, de origens francesa, belga e húngara que influenciaram a educação matemática no Brasil,são apresentados ao leitor: Dienes e Golding, George e Frédérique Papy, Caleb Gattegno, Zoltán Dienes, Lucienne Felix e Jean Dieudonné. Alguns deles, segundo Bia, apresentavam ideias conflitantes entre si.

No terceiro capítulo da tese, ela organiza os dados coletados em dez temas:

\section{A evolução das ideias sobre Matemática Moderna no currículo}

O programa brasileiro de matemática era muito tradicional até a década de 1950. A partir daí, nos congressos nacionais de educação matemática, as ideias da Matemática Moderna começaram a ser discutidas e aplicadas no Ensino Médio e, posteriormente, no Fundamental. A abordagem dos tópicos foi realizada através da linguagem da teoria dos conjuntos e das estruturas algébricas.

Segundo Soares (2005), nos três primeiros dos cinco congressos organizados no Brasil à época $(1955,1957,1959)$, as ideias da Matemática Moderna estiveram timidamente em pauta e, apresentaram-se fortemente nos dois últimos $(1962,1966)$.

O I Congresso Nacional de Ensino de Matemática no Curso Secundário aconteceu em Salvador (BA), no mês de setembro de 1955, com o objetivo principal de tratar de assuntos como os programas e os currículos, o livro de classe e as "tendências modernas do ensino", além do aperfeiçoamento dos professores de Matemática. Mas não foi feita nenhumamenção à Matemática Moderna.

No II Congresso Nacional de Ensino de Matemática, realizado em Porto Alegre, em 1957, que abrangeu, além do Ensino Secundário, o Ensino Primário e a Formação de Professores, foram estudados temas relativos à aprendizagem da Matemática nos diferentes níveis de ensino, à definição das bases para a elaboração de programas e à influência da Matemática nas demais disciplinas. O tema "Matemática Moderna" foi abordado, ainda que discretamente, nas teses de Ubiratan D'Ambrosio, Osvaldo Sangiorgi, Jorge Emmanuel FerreiraeMartha Maria de Sousa Dantas. 
O III Congresso Nacional de Ensino de Matemática ocorreu no Rio de Janeiro, em 1959. Seu objetivo foi estudar problemas inerentes aos ensinos secundário, primário, comercial, industrial e Normal, relativos ao ensino de Matemática. Ainda foram discutidas questões vinculadas à formação dos professores secundários. Nenhum assunto referente à Matemática Moderna foi abordado.

\section{O início do movimento no Brasil}

Os anos de 1960 marcaram o início do movimento da Matemática Moderna no Brasil, com o oferecimento do primeiro curso de formação em serviço de professores do Ensino Médio. O curso foi ministrado por professores norte-americanos, no estilo curso de verão. Segundo os entrevistados por Bia, Osvaldo Sangiorgi foi o pai desse movimento, liderando o Grupo de Estudos do Ensino da Matemática (GEEM).

O IV Congresso Nacional de Ensino de Matemática aconteceu em Belém (PA), em 1962. Este evento teve como objetivo a introdução da Matemática Moderna no ensino. Valente (2006) atribui esse movimento à presença de congressistas ligados ao GEEM. Foram realizadas aulas, apresentações e palestras relativas à introdução da Matemática Moderna na escola secundária.

No $V$ Congresso Nacional de Ensino de Matemática, organizado pelo GEEM, em 1966, na cidade de São José dos Campos/SP, o tema foi a Matemática Moderna na escola secundária e suas articulações com o ensino primário e com o ensino universitário. Foram criados grupos que discutiram os problemas da Teoria dos Conjuntos e de Lógica Matemática aplicadas ao ensino, os tópicos de Álgebra Moderna e Espaços Vetoriais e o tratamento moderno da Geometria e da Lógica Matemática. Também foi discutido o moderno programa de matemática, sugerido pelo GEEM posteriormente.

\section{O papel do Grupo de Estudos do Ensino da Matemática - GEEM}

Criado em 1961, sob a liderança do professor Osvaldo Sangiorgi, o GEEM teve um papel extremamente importante no movimento da Matemática Moderna no Brasil, ao assumir a liderança na implementação das mudanças, na oferta de cursos de formação de professores dos Ensinos Médio e Fundamental nos períodos de férias escolares, na elaboração dos programas de matemática escolares e na participação e na organização de diversas palestras, seminários, congressos e encontros. Nos anos iniciais do grupo, as atividades se concentraram principalmente no estado de São Paulo. Entretanto, a partir de 1966, o grupo de fato liderou o movimento, intensificou e expandiu suas atividades para todo o Brasil.

Dentre as principais atividades e contribuições do grupo, Beatriz cita os cursos de formação continuada para professores de matemática do ensino secundário e para professores do ensino primário; as diversas palestras destinadas a professores de matemática em todo o país; os encontros e os congressos; e as diversas publicações de livros didáticos e materiais para formação de professores. 


\section{0 envolvimento das universidades no movimento}

A participação de professores universitários no movimento da reforma da matemática não foi tão expressiva quanto a dos professores de Ensino Médio. E poucos professores universitários assumiram algum papel de liderança. Membros do GEEM acreditam que parte dos erros e dos exageros cometidos na tradução de livros do inglês poderia ter sido evitada se tivessem contado com a participação de matemáticos universitários, pois poucos livros foram escritos por esses profissionais.

\section{Influências externas}

As influências aconteceram através de material impresso produzido em outros países, traduzido para o português ou espanhol e utilizado no Brasil; do intercâmbio internacional de educadores matemáticos - professores de variados países: Springer/EUA, Ranucci/EUA, Pickert/Alemanha, Felix/França, Papy/Bélgica, Gattegno/Inglaterra e Dienes/Canadá, que estiveram no Brasil e ministraram palestras, impactando profundamente os professores brasileiros; e das agências de fomento, que subsidiaram financeiramente a participação de diversos brasileiros em cursos de verão no exterior, dentre eles Osvaldo Sangiorgi, Renate Watanabe, Rosa Feldman e Lafayette de Moraes.

\section{O papel dos livros didáticos e das editoras}

Como a oferta de cursos de capacitação não conseguiu atender à grande quantidade de professores de matemática do Brasil, em muitos casos o livro didático era a única fonte de informação dos professores, que deles extraíam os conceitos e as formas de apresentar os exemplos e os problemas a serem propostos, além da sequência a ser adotada.

Havia dois tipos de material didático: os de projeto e os comerciais. Os livros de projeto foram considerados difíceis pelos professores e demandariam a realização de oficinas para aprender a utilizá-los. Portanto, não se configuravam como interessantes financeiramente para as editoras. E esses livros acabaram sendo substituídos pelos livros comerciais. Muitas editoras solicitavam aos autores que produzissem livros tradicionais, mas que parecessem modernos, com linguagem ligeiramente diferente e que introduzissem um capítulo sobre a teoria de conjuntos. Esses livros eram mais atrativos para os professores, que os escolhiam em decorrência da familiaridade com a forma apresentada.

Outra mudança significativa que envolveu os livros didáticos foi a divisão entre o livro do professor e o livro do aluno. Este último se tornou um livro descartável, pois trazia atividades a serem desenvolvidas no próprio livro, sentenças para completar, diagramas para relacionar elementos, distinguir verdadeiro e falso. No geral, exigia pouco raciocínio e muito domínio da nova simbologia eda moderna linguagem matemática. 


\section{O papel do guia curricular oficial}

Cada estado brasileiro era responsável por supervisionar o currículo oficial das escolas. Bia escolheu o guia do estado de São Paulo para análise, porque esse estado foi o líder do movimento da Matemática Moderna no Brasil e seu documento serviu de modelo para a elaboração dos guias dos demais estados.

O guia paulista foi elaborado por uma equipe de professores de todos os níveis de ensino (do primário ao ensino superior) e apresentado como uma série de recomendações, elaboradas a partir de três pressupostos: a matemática é um sistema fechado que independe das outras disciplinas, a teoria dos conjuntos pode ser utilizada para unificar a matemática e a estrutura é uma característica subjacente à matemática. $O$ guia apresenta os temas matemáticos em quatro unidades: Relações e Funções; Campos Numéricos; Equações e Inequações; e Geometria.

Bia apresenta algumas reflexões sobre estes pressupostos: a matemática está relacionada a diferentes áreas do saber, e o guia poderia ter explorado essa interdependência; a teoria dos conjuntos, que deveria ter sido utilizada para unificar os temas, acabou tomando grandes proporções e perdendo essa característica; e a ênfase na estrutura comprometeu a compreensão intuitiva da matemática, dando espaço para definições muito rigorosas, o que provavelmente tornou o guia muito complicado para a maioria dos professores do nível básico.

Os livros didáticos produzidos a partir do guia também tinham as mesmas características. Devido à dificuldade de utilização desses livros pelos professores, as editoras produziam dois tipos de livros: aqueles que atenderiam ao estado de São Paulo, segundo seu guia, e uma segunda edição para o restante do país. A secretaria elaborou e distribuiu manuais para serem utilizados em substituição aos livros didáticos. Os manuais foram rejeitados pelos professores.

\section{Implementação da reforma curricular}

Foi marcada pela sequência de alguns acontecimentos, como a oferta de cursos de formação de professores em serviço, a reforma dos livros didáticos, a modificação dos exames de admissão às universidades, as mudanças implementadas nos programas das Escolas Normais e as novas exigências nos concursos de professores efetivos.

Bia comenta que, "embora esse movimento tenha atingido um número enorme de professores, tal empenho, por si só, não foi suficiente para mudar suas atitudes, crenças e práticas sobre o ensino de matemática" (D’AMBROSIO, 2017, p. 142). E relata que

defensores do movimento de reforma realizaram projetos que incorporavam novas ideias, porém foram tentativas isoladas de reforma e raramente compartilhadas entre os educadores matemáticos. Além disso, tais projetos eram, em sua maioria, realizados no setor privado ou em escolas especiais. (D'AMBROSIO, 2017, p. 144)

Ainda na tese, Bia apresentou alguns exemplos de projetos isolados desenvolvidos à época, como casos de sucesso ou não. 


\section{Formação e habilitação de docentes}

Uma das inovações nos cursos de formação em serviço foi aliar ao estudo do conteúdo a metodologia apropriada para ensiná-lo. Entretanto, como o tempo destinado a esses cursos era muito curto, eles não propiciaram uma mudança de atitude dos professores em relação ao ensino da matemática.

Beatriz cita Eden (1979, p. 30), ao afirmar que "a formação continuada é preferível ao treinamento intensivo, uma só vez". E ainda complementa:

para que a mudança ocorra, é importante trabalhar com os professores diretamente em suas escolas, ao longo de todo o ano escolar, orientando e observando seu trabalho. Isso é essencial para ajudar a desenvolver um sentimento de confiança e segurança nos professores, para que eles não retrocedam ao estilo tradicional de ensino expositivo e autoritário. (D'AMBROSIO, 2017, p. 148)

Os cursos de formação inicial de professores aconteciam nas Escolas Normais. Entretanto, em decorrência da grande expansão do sistema educacional brasileiro, dos professores em exercício, a maioria não era habilitada, pois o número de vagas era muito maior que 0 de profissionais formados. A pesquisa de Beatriz apresenta dados que confirmam a grande quantidade de professores atuando nas escolas sem a escolarização mínima exigida para o exercício do cargo ou com formação específica em outras áreas do conhecimento ao invés da licenciatura: ocorria, por exemplo, a contratação de engenheiros para lecionar matemática.

Posteriormente, a seleção de professores passou a ser realizada via concursos, que garantiam efetivação no cargo até a aposentadoria. Por isso, as provas dos concursos foram adequadas às necessidades do cargo e passaram a exigir conhecimentos relativos à nova matemática. O resultado, em 1976, como citado por Bia, foi uma reprovação em massa: 99,7\%. Em decorrência da Lei ํㅜ 5.692/71, que ampliou o acesso à educação, muitos cargos de professores estavam vagos. Por isso, outros concursos foram sendo realizados, com avaliações cada vez menos rigorosas, até que essas vagas foram preenchidas.

\section{As mudanças que ocorreram como resultado do movimento}

Antes da reforma de 1960, o programa de matemática era composto pelos conteúdos desenvolvidos antes do século 17. O mesmo acontecia com a metodologia utilizada para o seu ensino, na qual predominavam a memorização e o ensino autoritário.

A partir da reforma, mudanças foram percebidas, especialmente nas séries finais do Ensino Fundamental, em que foram introduzidas a linguagem da teoria de conjuntos e as ideias de estruturas algébricas. Apareceram as primeiras definições de incógnitas, que deveriam ser entendidas como o espaço em que um número seria inserido para tornar a expressão verdadeira - situação em que predominariam a exploração e a investigação. Entretanto, na tradução literal, a incógnita foi definida como o famoso "quadradinho", que deve ter o seu valor determinado através de um algoritmo mecânico. Houve também a redução do número de exercícios considerados difíceis e trabalhosos e dos problemas 
concebidos para a prática. Os livros didáticos passaram a ser extremamente detalhados e rigorosos matematicamente, apesar dos muitos erros conceituais. Bia preocupou-se em apresentar ao leitor algumas exemplificações.

\section{Considerações finais}

A partir dessa discussão, no quarto e último capítulo, além das conclusões, a Beatriz apresenta algumas recomendações:

- a troca de experiências entre países é muito interessante e deve ser incentivada, mas as recomendações precisam ser analisadas criticamente, preferencialmente por líderes e especialistas locais, que conheçam a realidade e a partir dela tomem as decisões necessárias;

- os mesmos cuidados devem ser observados em qualquer tentativa de inovação, a fim de garantir a compreensão do grupo sociocultural para o qual a inovação está sendo considerada;

- a participação de pesquisadores brasileiros em congressos e publicações internacionais deve ser ampliada;

- o controle da qualidade dos livros didáticos deve ser confiado a uma equipe competente e os professores precisam ser preparados para analisar criticamente esses livros;

- os cursos de formação inicial de professores devem receber melhorias;

- a ampliação dos cursos de capacitação oferecidos aos professores em serviço, deve garantir que deixem de ser apenas cursos condensados e possam, de fato, preparar o professor para superar a sua própria resistência;

- o envolvimento ativo dos professores no processo de inovação é essencial e pode ser estimulado, se lhes forem apresentados o quadro teórico e a filosofia por trás das propostas e oferecidos materiais facilmente utilizáveis em sala de aula;

- os pesquisadores brasileiros precisam ter clareza do ensino de Matemática no Brasil, das reais necessidades da sociedade e do currículo de matemática adequado a ela;

- a busca e o estudo de metodologias alternativas que permitam aos estudantes explorar os conceitos matemáticos através de situações problema a serem resolvidas precisam ser implementados.

Evidencia-se, na leitura da tese, que as ideias da reforma atingiram o Brasil através do intercâmbio internacional de pesquisadores e acadêmicos, da participação de brasileiros em conferências internacionais e da divulgação de livros e materiais didáticos. O olhar insubordinado de Bia se revela em diversos momentos da pesquisa, em especial ao comparar os objetivos dos diversos países envolvidos na reforma, pois os programas europeus e americanos se propunham a elevar a qualidade do ensino, enquanto o Brasil ainda tentava expandir quantitativamente o sistema educacional.

Segundo Bia, as inovações propostas pelo GEEM para o estado de São Paulo serviram de modelo para as outras regiões do país - um equívoco cometido,se considerada a diversidade das regiões brasileiras. Como grande parte dos professores 
não teve oportunidade de participar dos cursos de capacitação, as propostas da reforma foram disseminadas principalmente através dos livros e dos materiais didáticos comercializados. Isso, na visão arguta e insubordinada de Beatriz, inviabilizou uma real mudança na metodologia de ensino e nas crenças dos professores acerca do ensino e da aprendizagem da matemática.

Dentre algumas críticas apresentadas por ela quanto à condução da reforma, é importante destacar a interpretação errônea das propostas: uma linguagem extremamente inadequada para os professores em exercício; a tradução do marcador de lugar como "quadradinho" (que acabou sendo substituído posteriormente pela incógnita X); a abordagem por atividades, mal interpretada como aprendizagem através de brincadeiras (que acabaram acontecendo de forma desestruturada); o uso abusivo de giz colorido, na tentativa de fazer do ensino uma atividades moderna; a substituição da abordagem euclidiana da geometria pela abordagem baseada na álgebra linear (vetores e transformação); a disposição do conteúdo de geometria como o último do ano escolar (que acabava não sendo contemplado e comprometendo a formação dos estudantes neste assunto); a redução drástica do número de exercícios nos livros didáticos; a transformação desses livros em livro-caderno, o que inviabilizava o reaproveitamento do livro por outra criança e comprometia a possibilidade de brasileiros mais vulneráveis financeiramente de avançar nos estudos.

Beatriz ainda observou alguns aspectos positivos: a liderança do movimento não ficou ao encargo das universidades, mas de professores do Ensino Fundamental e Médio; o golpe militar de 1964 não interferiu significativamente na reforma do currículo da matemática escolar; os livros didáticos ficaram mais coloridos e fáceis de ler; a parceria estabelecida entre educadores matemáticos e comunidade de psicologia foi produtiva para a Educação Matemática; as primeiras Olimpíadas da Matemática estimularam o estudo da disciplina; nova área de interesse para pesquisadores foi criada e desenvolvida: a inovação curricular e a elaboração do guia curricular.

A leitura da tese é indicada para professores e pesquisadores que pretendem entender não apenas a reforma da Matemática Moderna no Brasil, mas também suas consequências para o sistema educacional atual. É igualmente indicada para os educadores que pretendem estudar e implementar inovações curriculares. Beatriz traz muitas considerações importantes para esse público. A postura insubordinada, visionária e construtivamente irreverente de Bia fornece à pesquisa atualidade e aplicabilidade incontestáveis, mesmo tendo se passado trinta anos.

\section{Referências}

D'AMBRosIO, B. S. Dinâmica e as consequências do movimento da Matemática Moderna na Educação Matemática do Brasil. Tradução Denise Negrão Rossi Piva. Campinas, SP: Mercado de Letras, 2017. (Coleção Insubordinação Criativa)

D'AMBROSIO, B. S.; LOPES, C. E. Trajetórias profissionais de educadoras matemáticas. 1. ed. Campinas, SP: Mercado de Letras, 2014. 
GUIMARÃES, H. M. Por uma matemática nova nas escolas secundárias: perspectivas e orientações curriculares da matemática moderna. In: MATOS, J. M.; VALENTE, W. R. (Org.). A matemática moderna nas escolas do Brasil e de Portugal: primeiros estudos. São Paulo: Da Vinci; CAPES-GRICES, 2007. p. 21-45.

SOARES, F. S. Os congressos de ensino da Matemática no Brasil nas décadas de 1950 e 1960 e as discussões sobre a Matemática Moderna. In: SEMINÁRIO PAULISTA DE HISTÓRIA E EDUCAÇÃO MATEMÁTICA, 1., 2005, São Paulo. Anais... São Paulo: IME USP, 2005. p. 445-452. Disponível emhttp://www.ime.usp.br/ sphem/documentos/sphemtematicos-5.pdfAcesso em: 15 ago. 2017.

VALENTE, W. R. A Matemática Moderna nas escolas do Brasil: um tema para estudos

históricos comparativos. Revista Diálogo Educacional -PUCPR, Curitiba, PR, v. 6, n. 18, p 19-34,2006.

Submissão: 02/08/2017

Aceite: 22/11/2017 